\title{
A LUDICIDADE NO PROJETO DE EXTENSÃO VIVÊNCIAS CORPORAIS LÚDICAS DA UFSC
}

Recebido em: 24/06/2018

Aceito em: 18/03/2019

\author{
Nicole da Rosa Cachoeira ${ }^{1}$ \\ Luciana Fiamoncini ${ }^{2}$ \\ Universidade Federal de Santa Catarina (UFSC) \\ Florianópolis - SC - Brasil
}

RESUMO: Em muitos programas de práticas corporais, a padronização dos movimentos é a forma de trabalho mais executada, não havendo espaço para reelaboração ou transformação daqueles. Nesse contexto, a ludicidade, a consciência corporal, não são valorizadas, esquecendo de contemplar a totalidade do ser humano. Sendo assim, este trabalho tem como objetivo descrever como a ludicidade é vivenciada pelos participantes do projeto de extensão intitulado Vivências Corporais Lúdicas da UFSC. Este estudo se caracteriza por uma pesquisa exploratória com abordagem qualitativa, na qual foram utilizados como instrumentos o diário de campo e entrevista semiestruturada. $\mathrm{O}$ estudo indica que o lúdico proporcionou a diversidade, fez florescer a afetividade e a integração das dimensões corporais, desenvolvendo as relações pessoais, afetivas e sociais, bem como contribuiu para uma maior entrega dos participantes.

PALAVRAS CHAVE: Lúdico. Corpo. Integração.

\section{THE PLAYFULNESS OF THE EXTENSION PROJECT ENTITLED VIVÊNCIAS CORPORAIS LÚDICAS OF THE UFSC}

ABSTRACT: In many programs of bodily practices, the standardization of movements is the most executed way of working, not having space for reelaboration or transformation of the same ones. Thus, the playfulness, the body consciousness, are not valued, forgetting to contemplate the totality of the human being. Therefore, this work aims to describe how the playfulness is experienced by the participants of the extension project entitled Vivências Corporais Lúdicas of the UFSC. This study is characterized

\footnotetext{
${ }^{1}$ Graduada no curso de Educação Física - Bacharelado na Universidade Federal de Santa Catarina (UFSC). Atua na área da Ginástica e da Dança como professora e bailarina, com ênfase na dança contemporânea e na dança jazz. Atuou como professora no projeto de extensão Vivências Corporais Lúdicas e no projeto Dança, Poesia e Movimento na UFSC. Além de possuir o curso de formação completa no Método Pilates.

${ }^{2}$ Graduada em Educação Física pela Universidade Federal de Santa Catarina, Especialista em Educação Física Escolar, Mestre em Educação pela Universidade Federal de Santa Catarina e Doutora em Educação Física da Universidade Federal de Santa Catarina. É professora efetiva do Centro de Desportos da Universidade Federal de Santa Catarina.
} 
by an exploratory research with a qualitative approach, in which the field diary and semi-structured interview were used as instruments. The study indicates that playfulness has provided diversity, has blossomed the affectivity and integration of body dimensions, developing personal, affective and social relationships, contributing to a greater commitment of the participants.

KEYWORDS: Playful. Body. Integration.

\section{Introdução}

Existem diversas propostas e programas de práticas corporais que são oferecidos como forma de desenvolver um corpo forte, esbelto e saudável. Em muitos desses programas, o corpo é trabalhado como um objeto ou como uma máquina, a fim de aumentar o auto rendimento e o condicionamento físico, visando à manutenção da saúde (BONETTI, 2006). A padronização dos movimentos é a forma de trabalho mais executada nesses programas, em que o profissional e os alunos somente reproduzem os movimentos e não os transformam.

A busca por um corpo saudável é o principal objetivo das pessoas que buscam os programas de atividade física, que, normalmente, estão atrelados a músculos fortes, grandes, definidos e a ausência de doenças, ou seja, apresentar um padrão "normal" considerado pela sociedade (CARVALHO, 2001). Nessa esteira, o desenvolvimento dos sentidos, a consciência corporal e a ludicidade são pouco valorizados, dando ênfase ao corpo físico, esquecendo de contemplar o ser humano em sua totalidade, com seus sentimentos e emoções.

A possibilidade dos participantes desses programas na reelaboração ou na criação de movimentos fica muito reduzida, o que pode não contribuir para o desenvolvimento de um corpo criativo, consciente e espontâneo. Nesse sentido, o corpo acaba "anestesiando as sensações", isto é, perdendo a capacidade de sentir e responder aos estímulos e a sensações que nos cercam (MILLER, 2012, p. 105). O homem passa 
Nicole da Rosa Cachoeira e A Ludicidade no Projeto de Extensão Vivências Corporais Lúdicas da UFSC Luciana Fiamoncini

a "funcionar" de forma mecanizada e automática, desequilibrando sua estrutura emocional, além de perder a profundidade de suas sensações.

Nessa ótica, a ludicidade vem como uma forma de potencializar as capacidades e qualidades do corpo que estão sendo apagadas e desvalorizadas em algumas práticas corporais, proporcionando o desenvolver da criatividade, da espontaneidade, para um corpo presente e sensível aos estímulos e a vivências (SOARES, 2013). A ludicidade é capaz de propiciar também a ampliação dos sentidos, a interação com o mundo à nossa volta e com as pessoas presentes. Além disso, por meio da espontaneidade, o lúdico não se apropria de rótulos e de máscaras, mas permite que o imprevisível aconteça.

Dessa forma, o processo lúdico abre caminhos para despertar o corpo de todo esse distanciamento corporal (MILLER, 2007), mediante dinâmicas interativas, nas quais os alunos são levados a explorar, experimentar e reconhecer o seu corpo e o do outro, deixando fluir toda a sua personalidade e estando atento para receber os estímulos do ambiente. Sendo assim, as atividades lúdicas devem permitir e resgatar a vivência de forma plena. Mesmo que a pessoa não esteja disposta a iniciar o exercício, a própria ludicidade deve fazer com que ela se entregue, de forma inteira, com seu corpo integrado (LUCKESI, 2005), proporcionando, assim, um corpo perceptivo e atento ao momento presente.

Essa concepção de trabalho corporal é fundamental, pois renova os diferentes modelos de aula de práticas corporais, possibilitando inúmeras formas de criação de movimentos e de abordagens do corpo. Segundo Rangel-Betti ${ }^{3}$ (1998, apud BONFIM, 2010), não há mais espaço para um professor de Educação Física que apenas reproduz o

\footnotetext{
${ }^{3}$ Rangel-Betti, I. C. Educação física e o ensino médio: analisando um processo de aprendizagem profissional. 1998. Tese (Doutorado em psicologia da educação). Universidade Federal de São Carlos. São Carlos, 1998.
} 
Nicole da Rosa Cachoeira e A Ludicidade no Projeto de Extensão Vivências Corporais Lúdicas da UFSC Luciana Fiamoncini

movimento e não o transforma. Logo, é necessário desenvolver profissionais reflexivos e críticos, sensíveis na sua formação e atuação.

Desse modo, o presente estudo tem como objetivo descrever como a ludicidade é vivenciada pelos participantes do projeto de extensão Vivências Corporais Lúdicas da UFSC.

\section{Metodologia}

Este estudo teve como base uma pesquisa exploratória com abordagem qualitativa. Optou-se pela pesquisa exploratória, pois ela tem como característica um planejamento flexível, permitindo conhecer o tema sob diversos ângulos e aspectos, além de envolver entrevistas com pessoas que tiveram experiências práticas com o problema pesquisado (PRODANOV; FREITAS, 2013).

O presente estudo foi realizado, no Centro de Desportos (CDS), na Universidade Federal de Santa Catarina (UFSC), mais, especificamente, no projeto de extensão, Vivências Corporais Lúdicas (VCL). As aulas do referido projeto ocorreram três vezes por semana, com duração média de 50 minutos.

De acordo com a característica desse trabalho, a idade dos participantes varia entre 47 e 67 anos, aproximadamente. Os sujeitos da pesquisa foram compostos por oito pessoas, adotando-se os seguintes critérios de inclusão: estar inserido há pelo menos um ano no projeto de extensão Vivências Corporais Lúdicas e ter frequência assídua nas aulas.

Foram utilizados como instrumentos para a coleta de dados a entrevista semiestruturada e o diário de campo, em que foram registradas falas e situações significativas para essa pesquisa, permitindo um aprofundamento dos fatos observados e 
o modo para compreendê-los. As entrevistas foram realizadas, individualmente, bem como em dias aleatórios. O diário de campo foi desenvolvido, de acordo com as dinâmicas executadas nas aulas, contendo as falas de alguns participantes, sensações, atitudes, olhares, comportamentos, dentre outros.

Todos os participantes da pesquisa assinaram o Termo de Consentimento Livre Esclarecido (TCLE), o qual abrange a voluntariedade da participação na pesquisa, a confidencialidade dos dados obtidos e a possibilidade da desistência de fazer parte do estudo, a qualquer hora, e por qualquer motivo, sem nenhum prejuízo para cada participante. A pesquisa foi aprovada pelo Comitê de Ética, em Pesquisa da Universidade Federal de Santa Catarina, sob o número de registro 1.768.609.

A interpretação dos dados foi realizada por meio da Análise de Conteúdo de Bardin (2009), em que foram identificadas duas categorias. Nessas categorias, procuramos abordar as principais características e abrangências acerca da ludicidade, os sentimentos manifestados e as experiências que a ludicidade proporciona aos participantes. Além disso, apresentou-se os aspectos mais importantes que estão presentes nas aulas e que favorecem o florescer da ludicidade no viver.

\section{O Lúdico - A Descoberta de Novos Caminhos}

"A etimologia do vocábulo lúdico, surge do latim ludus, que significa brincar ou jogar" (CARDOSO, 2008, p.57), porém, o termo lúdico não se refere somente à fase da infância. Com isso, é importante ressaltar que o lúdico é um termo abrangente e não faz referência somente ao ato de brincar. É também vivenciar a liberdade, a criação e a espontaneidade, bem como poder sentir as emoções, compartilhar risos, histórias e choros. 
Nicole da Rosa Cachoeira e A Ludicidade no Projeto de Extensão Vivências Corporais Lúdicas da UFSC Luciana Fiamoncini

O lúdico respeita a individualidade de cada pessoa, suas limitações e medos. Ele oferece a oportunidade para a exploração do desconhecido, a exploração por novos caminhos dos sentidos e dos movimentos, além de florescer a afetividade, promovendo a integração com o próximo.

O lúdico proporciona a expressão corporal, a autonomia do agir, no instante presente, liberando a espontaneidade e a personalidade de cada pessoa, por meio de dinâmicas que não visam ao rendimento. Desta forma, Bonetti (2006, p.65) afirma que:

O lúdico, normalmente, não acontece no cenário das atividades cotidianas dos seres humanos, pois não visa rendimento, produtividade, técnica, trabalho, mas é vivido e sentido nos momentos livres em uma outra dimensão, caracterizando uma das tantas possibilidades de o homem manifestar-se.

Assim, por meio da ludicidade ${ }^{4}$, mergulhamos em um mundo de fantasias e emoções, de criatividade de movimentos e pensamentos, de comunicação e construção de amizades. Isso possibilita o contato com a interioridade do ser humano, pouco explorada e requisitada nos dias atuais. Dentro deste contexto, por um lado, muitas pessoas se fecham e acumulam muita tensão no corpo. Por outro, muitas vezes, não exploram o brincar, o explorar, não experimentam algo novo. Dessa forma, a ludicidade busca lidar de outra forma com a realidade de compromissos e tensões, a fim de desenvolver a liberdade, o prazer e a felicidade no viver.

O trabalho corporal, com ênfase na ludicidade, tem como intuito desenvolver diversas potencialidades que estão "apagadas" e desvalorizadas pela sociedade atual. Geralmente, em uma aula de prática corporal, a maioria das pessoas não estão realmente presentes em sala, estão distantes, desatentas com o corpo e executam movimentos de

\footnotetext{
${ }^{4}$ Ludicidade: Neologismo do termo Lúdico, devido à necessidade de contemplar novos significados a palavras já existentes.
} 
Nicole da Rosa Cachoeira e A Ludicidade no Projeto de Extensão Vivências Corporais Lúdicas da UFSC Luciana Fiamoncini

forma inconsciente. Por isso, o processo lúdico abre caminhos para despertar o corpo de todo esse distanciamento corporal (MILLER, 2007). Mediante dinâmicas interativas, os alunos são levados a explorar, experimentar e reconhecer o seu corpo e o do outro, deixando fluir toda a sua personalidade e estando atento para receber os estímulos do ambiente.

Segundo Soares (2013), a ludicidade abrange principalmente as sensações de prazer e o estado de plenitude, a experiência introspectiva que cada pessoa obtém por meio da atividade lúdica. Além de proporcionar o aumento do nível de consciência para determinada atividade, proporciona também a expressão de sentimentos por intermédio de variadas linguagens comunicativas, como fala, gestos, gritos, movimentos, risos. Luckesi (2005, p.2) também afirma que "brincar, jogar, agir ludicamente, exige uma entrega total do ser humano, corpo e mente, ao mesmo tempo. A atividade lúdica não admite divisão e as próprias atividades lúdicas, por si mesmas, conduzem-nos para esse estado de consciência".

Além do estado de plenitude e das mais diversas sensações que o lúdico proporciona outro aspecto muito importante a se destacar é a integração entre as pessoas, a socialização que a vivência do lúdico oferece. Além da experiência interna, a atividade lúdica é também uma experiência socializadora, que promove a integração e o convívio com outras pessoas, estabelecendo assim relações no âmbito emocional e social (PATURY, CARDOSO; 2012). Essa concepção de ludicidade propõe o envolvimento de um corpo integrado e não fragmentado, focalizando a atenção para o instante presente. A presença está intimamente ligada à escuta corporal, à observação dos sentidos, do corpo no espaço e tempo. "Esse corpo presente possibilita o estado ao vivo, ou seja, do corpo vivo, espontâneo e atento aos acontecimentos e sensações do 
Nicole da Rosa Cachoeira e A Ludicidade no Projeto de Extensão Vivências Corporais Lúdicas da UFSC Luciana Fiamoncini

tempo presente. É como se pedisse em voz ativa, presente: Desliguem o piloto automático!" (MLLER, 2007, p.61-62). Este "estado vivo" de corpo abre espaços para a criatividade e a exploração de movimentos, proporcionando um corpo livre, disponível para dançar, brincar e criar.

\section{Vivências Corporais Lúdicas}

O projeto de extensão Vivências Corporais Lúdicas foi desenvolvido, a partir da tese de doutorado da Professora Albertina Bonetti, em março de 2006. Foi realizado, no Centro de Desportos da UFSC, voltado para pessoas com doenças aterosclerótica coronariana (DAC). Um dos objetivos da tese era desenvolver o programa Vivências Corporais Lúdicas e analisar suas contribuições para um modo de viver mais saudável de pessoas com DAC (BONETTI, 2006).

O projeto teve como perspectiva proporcionar a ludicidade, a diversidade de movimentos, incluindo vários elementos da cultura corporal, a saber: a dança, a ginástica, a capoeira, os jogos, a yoga e outras manifestações corporais. Visa desenvolver não somente as capacidades físicas, mas englobar o indivíduo na sua totalidade, com seus sentimentos e emoções (BONETTI, 2006). As aulas foram planejadas de modo a não serem repetitivas, mas buscam a variedade dos temas e dos movimentos corporais, levando o aluno adquirir um conhecimento novo a cada aula e tenha expectativa para o próximo encontro.

As práticas corporais vivenciadas no projeto são diversificadas, abordando todas as facetas do corpo humano; o corpo brincante, o corpo dançante, o corpo forte, sempre com a intenção de trabalhar o ser humano em sua totalidade, sem fragmentá-lo, trabalhando com vivências de dança, alongamento, ginástica exercícios de equilíbrio e concentração, jogos, yoga, tai chi chuan, dentre outras práticas (WOMMER et al., 2013, p.963). 
Nicole da Rosa Cachoeira e A Ludicidade no Projeto de Extensão Vivências Corporais Lúdicas da UFSC Luciana Fiamoncini

As vivências da pesquisa buscam desenvolver a autonomia e o autoconhecimento dos participantes, descobrir novas formas de se mover pelo espaço e outras formas de expressão dos sentimentos, fazendo com que eles sejam os protagonistas do seu próprio movimento e se tornem capazes de autorregular seu corpo em suas dimensões físicas, cognitivas, sociais e psicológicas.

A afetividade é outro elemento trabalhado, nessa proposta, pois as vivências buscam integrar os participantes por meio dos jogos e dinâmicas cooperativos, promovendo a interação, a aproximação e o relacionamento com outras pessoas (BONETTI, 2006). Essas interações fazem com que os participantes compartilhem suas experiências e histórias de vida, suas emoções, desabafos e incertezas. Nessa perspectiva, o projeto Vivências Corporais Lúdicas oferece a construção de um laço de amor, busca construir uma família, uma relação de pura amizade com o próximo.

A ludicidade é o elemento que caracteriza o projeto, pois proporciona prazer, alegria, descontração e integração entre os participantes. Dessa forma, as atividades têm como meta abordar o lúdico, permitindo-se ao desconhecido, à liberdade de expressão. No que concerne a essas atividades, busca-se desenvolver a criatividade, a fantasia, o prazer com seu corpo e com o movimento do outro (WOMMER et al., 2013). Dinâmicas de massagem, de tocar, sentir o seu corpo e o do outro são também desenvolvidas, nessa pesquisa, que levam a pessoa à conscientização do movimento, à sensibilidade, ao autoconhecimento, ao bem-estar e ao relaxamento.

Sendo assim, este trabalho busca desenvolver a linguagem corporal, o refinamento dos sentidos e a experimentação de movimentos, proporcionando vivências que buscam a expressão da vida (BONETTI, 2006). Atualmente, o projeto é voltado 
Nicole da Rosa Cachoeira e A Ludicidade no Projeto de Extensão Vivências Corporais Lúdicas da UFSC Luciana Fiamoncini

para pessoas da comunidade, acima de quarenta anos, bem como pessoas que apresentam algum tipo de doença ou riscos, como: diabetes, artrite, artrose etc.

\section{Resultados e Discussão}

\section{Experiências Afetivas: A Integração e o Despertar do Corpo}

Segundo Santin (1994), o significado da palavra ludicidade está relacionado com a criatividade, a imaginação, a liberdade, a participação, a interação, a autonomia e outros termos de infinita riqueza e qualidades que englobam a palavra. A ludicidade, assim como o lúdico, são termos abrangentes que vão além do brincar, do jogar, da diversão. Eles envolvem uma série de fatores que estão relacionados e interagem entre si. É uma troca de sentimentos e interesses contemplados na imaginação e na criatividade de cada pessoa.

A partir desses pressupostos, pode-se dizer que uma atividade lúdica envolve muitos aspectos, dentre eles: os momentos de espontaneidade que proporciona uma aprendizagem de forma natural, gradativa e não de maneira forçada (PATURY e CARDOSO, 2012). Sendo assim, as atividades lúdicas englobam vários aspectos, proporcionando um estado de viver os diversos elementos que compõe o nosso corpo.

A ludicidade experienciada, nesse estudo, foi enfatizada pelos participantes, sendo percebida nas suas relações pessoais, afetivas e sociais, tais como: com a família, com os amigos, em brincadeiras entre familiares, em uma conversa. Além disso, nos momentos de práticas artísticas, como: uma pintura, um recorte ou costura. Isso é observado nas falas dos entrevistados:

É uma troca de gestos, de olhares, de pensamentos. A todo momento, o lúdico esta presente na minha vida, se a gente fica carrancudo a gente está se isolando, se a gente coopera a gente está transmitindo, então tem essa troca de sentimento, de calor, de amor, de carinho, tudo 
isso, ou às vezes de braveza, de revolta, e a todo momento que você encontra outra pessoa, você está manifestando essa parte (Roberto).

Então, os momentos lúdicos do meu dia a dia são quando eu faço alguma arte, que eu invento, eu pinto, eu recorto, eu costuro, essas coisas assim, que é o meu momento lúdico, eu acho que é por aí mesmo, quando faço as minhas artes (Mercedes).

Amarilha (1997) também destaca a ludicidade, nas relações com a coletividade e consigo mesmo, presente, até mesmo, na compreensão de textos e nas histórias que ficarão marcadas na lembrança.

A falta de tempo foi outro ponto destacado com grande relevância, nas entrevistas, em relação à presença do lúdico, no cotidiano, bem como outros pontos: a questão das situações de vida, na sociedade contemporânea, mais especificamente, os compromissos, as exigências do cotidiano que nos impedem muitas vezes de reconhecer e vivenciar os momentos lúdicos. Como pode ser observado nas falas a seguir:

Às vezes, a gente entra numa dinâmica do dia a dia de coisas que você tem que fazer, e a gente não entra em um sentir... Não dá tempo de você conversar, não dá tempo de você parar [...] pela situação do dia a dia e da família. Sinto falta disso, porque eu gosto. O que me deixa assim muito bem, [...] é você poder rir, poder brincar, poder dançar [...]. A gente tem que rever, mas é que realmente, é exigido, a sociedade, as coisas, o mundo está exigindo muito de você [...] (Zenilda).

Mas eu acho que na vida contemporânea, não sei se é só na contemporânea, eu acho que no passado também era assim, nem sempre as coisas acabam sendo lúdicas, quando dá para transformar qualquer problema em algo lúdico é ótimo [...], mas na vida moderna, e a vida de mulheres trabalhadoras, nem sempre é fácil [...] (Ilse).

Nesse depoimento, é notório que as próprias entrevistadas sentem falta da ludicidade, no dia a dia, devido às exigências da sociedade atual, do trabalho, dos afazeres e compromissos que impedem muitas vezes de demonstrar o afeto, um sentimento, de trocar experiências, risos ou até mesmo um abraço. 
Nicole da Rosa Cachoeira e A Ludicidade no Projeto de Extensão Vivências Corporais Lúdicas da UFSC Luciana Fiamoncini

Oliveira (1997, p.12) relata a relação da ludicidade com a sociedade moderna, propondo uma crítica da vida cotidiana com as práticas lúdicas, em que "as necessidades da produção econômica não são coincidentes com as necessidades humanas [...]". Nesse sentido, viver a ludicidade, na realidade da vida moderna, está cada vez mais difícil, sendo o aspecto lúdico considerado praticamente como uma ruptura com a sociedade contemporânea. Nas falas, fica implícito também a questão do tempo como sinônimo de dinheiro, não podendo ser desperdiçado com vivências lúdicas, "com seus componentes singelos de alegria, fundando outro tempo e redefinindo o espaço, assim como combinando regras estritas com a mais autêntica liberdade [...]"' (p.14-15).

A integração, a socialização e o relacionamento com as pessoas foram elementos muito presentes, nos depoimentos de vários participantes do projeto, proporcionando a construção de novas amizades, o aprendizado e o desenvolvimento das relações pessoais, de como interagir, como se relacionar. Isso é observado nas falas seguintes:

O que eu aprendi com o projeto, além do desenvolvimento físico, é o desenvolvimento pessoal mesmo, de interagir com as outras pessoas, de respeito, de amizade [...] (Mercedes).

E com o andamento do projeto, eu aprendi a ver que nós, seres humanos, cada um tem uma personalidade diferente e, que eu não precisava está me podando, me policiando, me afastando, procurar interagir, procurar ajudar, eu sendo instrumento de ajuda para aquelas pessoas [...]. Então o que eu aprendi é tentar no projeto [...] procurar me integrar com os outros e as pessoas novas, pelo menos se elas te dão abertura você consegue estar mais juntas com ela, se não, você respeitar o espaço do outro [...] (Zenilda).

Neste último depoimento, percebem-se outros fatores importantes na integração: a individualidade e as diferenças de personalidade de cada pessoa, bem como o aprendizado em relação a respeitar essas diferenças pessoais. Ainda, de acordo com 
Nicole da Rosa Cachoeira e A Ludicidade no Projeto de Extensão Vivências Corporais Lúdicas da UFSC Luciana Fiamoncini

Oliveira (1997), o lúdico pode proporcionar uma relação em que as pessoas se reconheçam como iguais e diferentes, que reconheçam as diferenças pelas singularidades que lhes são próprias, "é preciso que a amizade não diminua as diferenças e que as diferenças não diminuam a amizade" (WEIL, 1966, p.49). No depoimento, a seguir, por exemplo, podemos perceber, novamente, o aprendizado das relações sociais em que foi proporcionado pelas vivências no desenvolvimento do projeto:

[...] a gente conhece pessoas, otimista, pessimista, que topa tudo, que não topa nada, que são alegres, outras extrovertidas, outras não gostam de brincadeiras, outras gostam, então a gente tem que só saber aonde... E como se comportar diante dessas pessoas, ou se comportar do jeito que a gente é, para ver as consequências (risos). [...] Teve algumas pessoas que eu fui mais aberto do que outras, tem outras que realmente são mais recusas, outras são mais abertas mesmo, então foi essa, a mudança, mas não é uma mudança, é só uma aprendizagem, porque está convivendo com pessoas diferentes (Roberto).

Nessa perspectiva, durante as dinâmicas, a socialização permanece, de forma intensa, interferindo na afetividade com o próximo, possibilitando uma entrega maior dos participantes para com os outros e o aprendizado das relações sociais. De acordo com Salomão, Martini e Martinez, (2007, p.11), “o afeto pode ser uma maneira eficaz de se chegar perto do sujeito e a ludicidade, em conjunto, um caminho estimulador e enriquecedor para se atingir uma totalidade no processo de aprender, e aprender brincando". Nesse sentido, o afeto disponibiliza uma abertura maior para se viver a ludicidade, na sua totalidade, integrando os aspectos do sentir, do agir e do pensar, podendo estar presente no interior das relações sociais ou no interior das relações consigo mesmo.

Segundo Cardoso (2008), as atividades lúdicas, além de propiciarem experiências internas, enriquecem suas experiências externas, a saber: troca de relações 
Nicole da Rosa Cachoeira e A Ludicidade no Projeto de Extensão Vivências Corporais Lúdicas da UFSC Luciana Fiamoncini

com este tipo de ambiente e compartilhamento de histórias, de afeições. Além disso, é um grande agente socializador, sendo uma atividade com grande potencial interativo. Luckesi (2005) afirma ainda que o grupo é um fator condicionante e fundamental para a entrega em uma atividade lúdica, em que a coletividade, a partilha e a energia deste estimulam a ludicidade. Sendo assim, nota-se que a integração proporcionou uma maior entrega dos participantes com o próximo e consigo mesmo, originando laços de amizades e mudanças de comportamento.

Quando foi perguntado sobre a importância do lúdico e quais os sentimentos que essas vivências lúdicas despertavam nos entrevistados, os principais sentimentos manifestados foram o sentir-se bem, o sentimento de prazer e de alegria. Alguns entrevistados relataram também que a ludicidade faz com que se sintam mais à vontade e realizados nas vivências. Segundo Soares (2013), os sentimentos de prazer e bem-estar fazem com que as pessoas se envolvam com maior intensidade nas experiências, sendo esses os aspectos que contribuem para o estado de ludicidade.

No que diz respeito à importância do lúdico, todos os entrevistados consideraram o aspecto lúdico muito importante de ser trabalhado e de estar presente, nas aulas, por proporcionarem esses sentimentos de prazer e a integração com as pessoas, como já foi relatado anteriormente. De acordo com Patury e Cardoso (2012), as atividades lúdicas propiciam, principalmente, momentos de integração e de prazer, sendo esses os sentimentos mais aflorados nos participantes. Sendo assim, a ludicidade foi explorada, em vários momentos: nas dinâmicas, nas vivências, nos encontros; e, principalmente, na relação com outras pessoas, na troca de afeições, resgatando sentimentos de prazer, alegria e bem-estar. 
Nicole da Rosa Cachoeira e A Ludicidade no Projeto de Extensão Vivências Corporais Lúdicas da UFSC Luciana Fiamoncini

\section{Diversidade e Totalidade: A Busca por Novas Formas...}

Atualmente, podemos refletir sobre a totalidade do ser humano que está sendo esquecida na maioria das práticas corporais. Essas práticas são marcadas pela fragmentação e pela inconsciência dos movimentos corporais, que acabam por deixar apagada a singularidade de cada corpo.

Preciosos contornos esses em que o lúdico assume feições de jogo, desencavando profundezas relegadas trazendo à tona situações singelas, porém densas em graça, alegria, beleza, encantamento. [...] Ocorre, contudo, que o movimento pelo qual se pulverizam práticas e consciências produz, simultaneamente, necessidade nos sujeitos sociais de recompor aquilo que está se perdendo. E não é pouco o que está em jogo. É a nossa capacidade de nos reconhecermos nas práticas que realizamos; é, enfim, a oportunidade de redescobrir viva dentro de nós a seiva que nos liga a raízes comunitárias de uma vida em comum, na qual os outros homens são iguais a nós em direitos e, ao mesmo tempo, diferentes no jeito de ser (OLIVE1RA, 1997, p.28).

A partir deste pressuposto, pode-se refletir sobre a realidade em que vivemos, hoje, marcada pela fragmentação corporal. A totalidade abordada, neste trabalho, referese às várias dimensões em que constituem a condição humana. Com isso, de acordo com João e Britto (2004), essas dimensões incluem o aspecto físico, emocional-afetivo, mental-espiritual e sócio-histórico-cultural, os quais agem, de forma integrada, em uma única cadeia. Essas dimensões que envolvem o ser humano são indissociáveis e contribuem para a sua totalidade. Nessa perspectiva, o ser humano é compreendido como um ser complexo, regado por vários elementos essenciais para a sua existência.

As diversas dimensões que envolvem o ser humano precisam estar interagindo entre si, de forma harmônica e equilibrada, não somente um aspecto prevalecendo sobre o outro. Dessa forma, o equilíbrio das dimensões que envolvem o ser humano vão proporcionar a saúde no âmbito da sua totalidade. 
Nicole da Rosa Cachoeira e A Ludicidade no Projeto de Extensão Vivências Corporais Lúdicas da UFSC Luciana Fiamoncini

Tendo em vista a ideia de que a maioria das práticas corporais abordam o ser humano, de maneira fragmentada, com exercícios repetitivos e padronizados (BONETTI, 2006), um aspecto muito importante ressaltado, na entrevista, foi em relação à diversidade das práticas e às várias experiências que as aulas proporcionam. Como exemplo, é notório na fala a seguir:

[...] Dentro desse conjunto de várias atividades, eu acho que isso é a riqueza, uma coisa que é a brincadeira, mas uma brincadeira mais competitiva, às vezes, não tão competitiva também etc., mas é uma brincadeira, outra é mais um exercício, outra é uma dança. São essas várias atividades diferenciadas, que a aula acaba sendo uma coisa tão rápida, que você até fica pedindo um pouco mais. [...] Mas esses três anos eu acho que foi o que eu gostei mais, não só porque eu acho que contemplo uma variedade maior de alternativas de ensino, de prática dos alunos, com mais elementos eu acho, a gente saia de um já ia para outro, uma coisa diferente essa dinâmica (Ilse).

Achei as aulas sempre muito interessantes. Porque elas mudam a cada encontro, é uma surpresa, tem dança, tem ginastica, tem yoga, tem alongamento, tem de tudo, e são sempre dinâmicas, sempre pontual, sempre animada e a gente convive também com as outras pessoas, tem exercício também de olhar no olho, tem exercício de equilíbrio, é muito interessante, bem completo (Mercedes).

As aulas eu achei excelentes porque sempre tinha uma novidade, então a gente tinha uma dança diferente, uma brincadeira diferente, às vezes, repetia, mas parecia que a gente fazia de outra forma [...] (Roberto).

Nesses depoimentos, percebe-se que uma das características marcantes do projeto é a diversidade das práticas, as inúmeras dinâmicas que proporcionam experiências e conhecimentos corporais diversificados para os participantes. Bonetti (2006) também encontra o aspecto da diversidade como eixo central da proposta, nas falas dos participantes, sendo essa a principal motivação para as pessoas aderirem ao programa e permanecerem nele.

A ludicidade também é destacada como um elemento presente em outras atividades realizadas, sendo difícil analisar a ludicidade, de forma isolada, pois ela está 
Nicole da Rosa Cachoeira e A Ludicidade no Projeto de Extensão Vivências Corporais Lúdicas da UFSC Luciana Fiamoncini

presente, na educação somática, na dança e em outras vivências que são abordadas nas aulas. Nesse caso, segundo Oliveira (1997), a abrangência lúdica não admite divisões entre a execução de alguma tarefa e os sentimentos de prazer, de liberdade. Além do mais, todos os sentimentos que a ludicidade traz consigo devem estar em união com o fazer, com a execução de alguma atividade.

Eu acho que é difícil você separar o lúdico dos outros aspectos específicos da prática, mas como ele está praticamente em todas as práticas, há uma diversão que vai do começo ao fim da aula, eu acho que isso torna a aula leve. Porque muitas vezes o que acontece na educação física, na minha experiência anterior, você sai um pouco cansado da aula, porque você fez um esforço grande no exercício etc. Aqui, eu tenho a impressão que a gente fez os mesmos exercícios, tem o mesmo retorno, mas com um esforço muito mais disseminado dentro da prática, equilibrado. Então, eu acho que justamente isso, o carácter lúdico, proporciona isso de você não sentir o peso da atividade, eu pelo menos não sinto muito, não é um peso as aulas (Ilse).

Com isso, observa-se que o carácter lúdico influenciou, na própria intensidade das dinâmicas e vivências, proporcionando a realização das atividades, de forma harmônica, prazerosa, e não cobrança e/ ou obrigação, interferindo até mesmo no cansaço.

A ludicidade, segundo Luckesi (2005), estará presente na pessoa que conseguir, ao mesmo tempo, estar entregue à atividade, ao corpo e à mente. Para este autor, "a atividade lúdica não admite divisão e as próprias atividades lúdicas, por si mesmas, nos conduzem para esse estado de consciência" (p.2). Soares (2013) também afirma que as sensações de prazer e o estado de plenitude deverão ser alcançados nas atividades lúdicas, e que a própria ludicidade deve abranger a totalidade, a integralidade do ser humano. Dessa forma, no depoimento a seguir, nota-se o estado de presença alcançado, 
Nicole da Rosa Cachoeira e A Ludicidade no Projeto de Extensão Vivências Corporais Lúdicas da UFSC Luciana Fiamoncini

em que pensamentos e distrações não interferiram nas dinâmicas, permitindo viver a ludicidade em plenitude.

[...] O lúdico faz com que a gente fique um pouco mais desinibido, mais à vontade, mais alegre, esqueça um pouco dos problemas, porque naqueles momentos que a gente passa ali, só pensa naquilo, e não está pensando em outras coisas que está ocorrendo fora (Roberto).

Nas entrevistas, a diversificação e a presença da ludicidade propiciaram um comparativo com as outras práticas que são realizadas, atualmente, de forma repetitiva e mecanizada, como é observado nos depoimentos abaixo:

[...] Vou fazer um comparativo com outras atividades, que são atividades basicamente rotineiras, você vai malhar ou você vai fazer exercícios de alongamentos que são sempre repetitivos, e você está procurando um resultado, ou você quer ficar com o corpo durinho, ou você quer ficar mais fortão e etc. Mas aqui não, aqui a gente faz de tudo, e isso acrescenta no corpo, na mente, no teu modo de seguir depois, de comportamento, de relacionamento com as pessoas, eu acho que ele é muito rico o projeto, porque ele tem todas as dinâmicas assim, ele é bem completo, você não vem aqui só para um objetivo, você tem inúmeros objetivos, cada um busca o que vai lhe fazer bem, e ainda leva outras coisas de presente (Mercedes).

Eu me sinto bem, gosto muito dessa diversificação, é lúdico, lúdico mesmo, pelo meu conhecimento nós só temos aqui, você não tem outro lugar [...]. Em outros lugares, é mecanizado, é uma coisa assim mais com outras estruturas (Zenilda).

Além desses elementos que originaram uma comparação com outras práticas, outro fator levantado e identificado, no diário de campo, é a questão da individualidade que as dinâmicas oferecem e estão presentes em cada participante. Cada pessoa do projeto possui uma singularidade, uma personalidade diferente. Nesse contexto, consequentemente, os entrevistados apresentam limitações e necessidades diferentes, cada um na sua individualidade, constituindo o todo. Com isso, no diário de campo, foi relatado como as diferentes dinâmicas realizadas, nas aulas, abordam diferentes necessidades dos participantes. 
No decorrer das aulas, as diferentes dinâmicas realizadas, sejam elas brincadeiras lúdicas, danças, exercícios físicos, seja qual for o tema e o direcionamento corporal, se estiverem sendo desenvolvidas com base na totalidade do ser humano, contemplando suas diferentes dimensões, irão atender as diferentes individualidades em uma só atividade, em uma só dinâmica (17/08/2016).

Outro exemplo característico da abrangência da individualidade, nas aulas, presente no diário de campo, foi em relação a uma atividade de criação de três movimentos diferentes. Após criar esses movimentos, os alunos deveriam demonstrar e compartilhar suas criações com todos da turma. Após essa atividade, foi reservado um momento para argumentação e discussão da atividade proposta, no qual se obteve diferentes olhares e direcionamentos para as limitações de cada discente.

Durante o momento de discussão da dinâmica, Roberto relatou a respeito da criação, que ele possuí grande dificuldade em criar, pois há todo momento nas aulas de ginástica você é comandado, você está recebendo ordens sobre o que fazer e como fazer. E ainda refletiu que não é apenas nas aulas de ginástica, mas que a vida também é assim, cheia de regras e de cumprir obrigações. Já para Mercedes, a criação não é algo difícil, mas o maior desafio foi em relação à crítica, ao julgamento final, o olhar das outras pessoas em relação ao que ela criou, a opinião das pessoas. Já para Flor, foi um momento para brincar, descontrair e relaxar, sendo que o aspecto da ludicidade se fez bastante presente $(04 / 07 / 2016)$.

Segundo Brikman (2014), o trabalho em grupo deve proporcionar o crescimento pessoal de cada pessoa. "Esse crescimento se manifesta com atitudes e iniciativas de propor sequências ou movimentos, entre outros. Procura-se propiciar a cada um a oportunidade de contribuir com o grupo" (p. 57). Nessa perspectiva, segundo a autora, esses momentos de crescimento podem se originar por meio de sequências ou movimentos espontâneos, que sejam coerentes com o trabalho, o qual está sendo enfatizado na aula.

Para finalizar esta categoria, buscou-se relatar possíveis mudanças corporais, sentimentais, de comportamento, que foram manifestadas nas aulas. Sendo assim, o 
Nicole da Rosa Cachoeira e A Ludicidade no Projeto de Extensão Vivências Corporais Lúdicas da UFSC Luciana Fiamoncini

aspectos mais enfatizados, nos depoimentos, foram a questão da convivência com o próximo e das relações sociais, assim como o aprendizado que essas convivências com diferentes pessoas ocasionaram, e a relação com as questões de suas próprias vidas.

Eu acho que mudou na minha forma de ser, pensar [...] Eu acho que sim, cada vez a gente tenta melhorar, de me relacionar, de ser mais aberta com as pessoas, ficar mais à vontade pra falar, quando tiver vontade de falar (Amélia).

Eu aprendi muito, acho que eu aprendi muito mais sobre eu mesma. A minha vida foi naquele pânico, eu não saia de casa, não falava com ninguém [...]. Mas o projeto me ajudou muito. As pessoas do projeto foram fundamentais. Até mesmo quando eu cheguei aqui no projeto, que me aceitaram, a aceitação do jeito mesmo que eu era, eu não falava com ninguém, e teve uma aceitação do grupo, eu colocava o que eu passava. Eu não tenho mais as crises, graças a Deus. Eu acho que foi no decorrer das aulas, eu acho que fui aprendendo, aprendi com um, com outro, o jeito de ouvir, às vezes a gente para e a pessoa ouve, naquelas rodas que a gente fazia [...] (Elzira).

A partir dessas falas, é notório que a convivência entre os participantes foi um fator de extrema importância, nas aulas, possibilitando novos laços de amizade, troca de saberes e aprendizados. Essa proximidade promoveu maior confiança entre todos, permitindo a livre expressão de seus sentimentos, anseios e necessidades.

Dessa forma, os participantes compartilhavam risos, histórias de vida, valores, reconhecendo suas diferenças, e, assim, respeitando a individualidade de cada um na sua forma de ser e expressar seus sentimentos. Nas vivências lúdicas, Bonetti (2006) encontra a socialização como um fator fundamental para a permanência dos participantes, no projeto, em que a convivência gerou uma rede de apoio para o enfrentamento e superação dos problemas de saúde e outras questões de vida nas quais os participantes se encontravam.

Segundo João e Brito (2004), é muito enriquecedor, quando as experiências vivenciadas, na sala de aula, proporcionam uma correlação com o cotidiano da pessoa, 
Nicole da Rosa Cachoeira e A Ludicidade no Projeto de Extensão Vivências Corporais Lúdicas da UFSC Luciana Fiamoncini

pois envolvem os aspectos físicos, emocionais-afetivos, cognitivos e sociais, além de estarem atreladas às descobertas pessoais, as quais objetivam o autoconhecimento. Essas experiências não devem acontecer somente, no campo pedagógico, na sala de aula, mas é necessário que estejam presentes também, nos estúdios e salas, onde ocorrem práticas corporais diversas, contribuindo para a formação de um ser humano integrado.

\section{Considerações Finais}

Diante da realidade que vivemos, de fragmentação e padronização do corpo, nas práticas, faz-se cada vez mais necessário o trabalho corporal, de forma integrada e diversificada, como forma de resgatar valores que já estão se perdendo, em nossa sociedade, como: a afetividade, a confiança, a escuta e a autenticidade. Nesse sentido, busca-se desenvolver a consciência corporal e a ludicidade dos participantes, fatores esses de extrema importância em qualquer prática corporal realizada para a abrangência de um corpo total.

Sendo assim, a ludicidade desenvolvida, no projeto, contribuiu para vivenciar a diversidade das práticas corporais, possibilitando diferentes experiências e conhecimentos. Com isso, esse aspecto da diversidade atrelada ao lúdico permitiu um comparativo com outras práticas corporais, por resgatar o prazer e a presença de um corpo integrado, sendo esses elementos pouco encontrados em outras práticas corporais que são oferecidas atualmente. Além disso, vale ressaltar que tanto o respeito a individualidade quanto o atendimento a diferentes necessidades, alcançaram diferentes objetivos e olhares nessa prática. 
Nicole da Rosa Cachoeira e A Ludicidade no Projeto de Extensão Vivências Corporais Lúdicas da UFSC Luciana Fiamoncini

A ludicidade também proporcionou uma forte integração e convívio entre os participantes do projeto. Essa integração, muito enfatizada nos depoimentos, fez florescer a afetividade, contribuindo para uma maior entrega daqueles, bem como assegurou o aprendizado das relações sociais. Outro aspecto relevante a ser ressaltado é a aceitação, aspecto esse em que os participantes aprenderam a respeitar as singularidades de cada pessoa, amenizando assim as características comportamentais deles.

Nesse sentido, o aspecto lúdico foi considerado um elemento importante para os integrantes, sendo reconhecido na vida cotidiana, principalmente, nos momentos de relacionamentos, com os amigos, familiar, netos, dentre outros.

Assim, é de extrema importância que os profissionais de Educação Física tenham um olhar mais ampliado do ser humano e das práticas corporais e uma consciência de que qualquer atividade ofertada deve contemplar os diferentes aspectos que formam o ser humano, e não somente sua dimensão física ou cognitiva, mas também suas dimensões sociais, emocionais, culturais e afetivas. Dessa maneira, é preciso que esse profissional tenha a capacidade de criar diferentes atividades e exercícios, além de pensar em possibilidades de re-significar as práticas corporais.

Por fim, acredita-se que a ludicidade contribuiu para a construção de um corpo integrado, sensível e consciente, nas práticas corporais, nas quais os sentimentos de prazer e liberdade despertados permitiram que os participantes vivenciassem as atividades com uma maior entrega, presença, durante as dinâmicas. Além do mais, proporcionou o aprendizado e maior abertura nas relações sociais, valorizando as singularidades de cada um. 


\section{REFERÊNCIAS}

AMARILHA, M. Estão Mortas as Fadas? Literatura Infantil e Prática Pedagógica. Petrópolis: Vozes, 1997.

BARDIN, L. Análise de Conteúdo. Lisboa: Edições 70, 2009.

BONETTI, A. O coração e o lúdico: vivências corporais para um viver mais saudável de pessoas com problemas cardiovasculares. 2006. 212 f. Tese (Doutorado em Enfermagem). Programa de Pós Graduação em Enfermagem, Centro de Ciências da Saúde, Universidade Federal de Santa Catarina, Florianópolis, 2006.

BONFIM, T. Corporeidade e educação física, 2010. Disponível em: http://www.unifafibe.com.br/revistasonline/arquivos/revistafafibeonline/sumario/9/1805 201 1140424.pdf Acesso em: 23 maio 2016.

BRIKMAN, L. A linguagem do movimento corporal. 3. ed., São Paulo: Summus, 2014.

CARDOSO, M. C. Baú de Memórias: Representações de ludicidade de professores de Educação Infantil. 2008. 170 f. Dissertação (Mestrado em Educação). Faculdade de Educação, Universidade Federal da Bahia, Salvador, 2008.

CARVALHO, Y. M. D. Atividade física e saúde: onde está e quem é o "sujeito" da relação. Revista Brasileira de Ciências do Esporte, Campinas, v. 22, n. 2, p. 9-21, jan. 2001.

JOÃO, R. B.; BRITO, M. d. Pensando a corporeidade na prática pedagógica em educação física à luz do pensamento complexo. Revista Brasileira de Educação Física e Esporte, São Paulo, v.18, n.3, p.263-272, jul./set. 2004.

LUCKESI, C. C. Ludicidade e atividades lúdicas - uma abordagem a partir da experiência interna. 2005. Disponível em: www.luckesi.com.br/artigoseducacaoludicidade.htm. Acesso em: 12 Jun. 2016.

MILLER, J. A escuta do corpo: sistematização da Técnica KlaussVianna. São Paulo: Summus, 2007.

Qual é o corpo que dança? Dança e educação somática para adulto e crianças. São Paulo: Summus, 2012.

OLIVEIRA, P. D. S. O lúdico na vida cotidiana. In: BRUHNS, H. T (Org.). Introdução aos estudos do lazer. São Paulo: Editora Unicamp, Cap. 1, 1997, p.11-30.

PATURY, F. M.; CARDOSO, M. C. Ludicidade na Formação Profissional do Professor: Um Olhar Atentivo. SEMANA DE PEDAGOGIA DA UESB: Memórias de um percurso formativo, 2012. Anais... Disponível em: http://www.uesb.br/eventos/semanapedagogia/?pagina=trabalhos-aprovados . Acesso em: 15 out. 2016. 
PRODANOV, C. C.; FREITAS, E. C. D. Metodologia do trabalho científico: métodos e técnicas da pesquisa e do trabalho acadêmico. 2. ed. Novo Hamburgo: Feevale, 2013.

RANGEL-BETTI, I. C. Educação física e o ensino médio: analisando um processo de aprendizagem profissional. 1998. Tese (Doutorado em psicologia da educação). Universidade Federal de São Carlos. São Carlos, 1998.

SALOMÃO,H. A. S.; MARTINI, M.; MARTINEZ, A. P. A importância do lúdico na educação infantil: enfocando a brincadeira $\mathrm{e}$ as situações de ensino não direcionado. Psicologia.pt, Lisboa, 2007. Disponível em: $<$ http://www.psicologia.pt/artigos/textos/A0358.pdf >. Acesso em: 12 out. 2016.

SANTIN, S. Educação física: da alegria do lúdico à opressão do rendimento. Porto Alegre: Edições EST/ESEF-URGS, 1994.

SOARES, D. T. Ludicidade como estados do corpo: a arte do palhaço imbricada na dança. In: ENCONTRO CIENTÍFICO NACIONAL DE PESQUISADORES EM DANÇA, 3, 2013. Anais...Universidade Federal da Bahia, p. 1-16, 2013.

WEIL, S. Attente de Dieu. Paris: Fayard, 1966.

WOMMER, D. et al. A influência do projeto vivências corporais lúdicas no processo de viver da pessoa com bipolaridade: um estudo de caso. Revista Pensar a Prática, Goiânia, v. 16, n. 4, p. 956-1270, out./dez. 2013.

\section{Endereço das Autoras:}

Nicole da Rosa Cachoeira

Rua Douglas Seabra Levier, 109 - B1 A, ap. 102-Serrinha

Florianópolis - SC - 88.040-410

Endereço Eletrônico: nicolecachoeira@gmail.com

Luciana Fiamoncini

Universidade Federal de Santa Catarina

Campus Universitário (Trindade)

Florianópolis - SC - 88.040-900

Endereço Eletrônico: lfiamoncini@yahoo.com.br 